\title{
LEARNING OBJECTIVES OF NEUROANATOMY FOR UNDERGRADUATE MEDICINE: A DELPHI PROCESS
}

\author{
Gabriela Claudia ${ }^{1 *}$, Siti Munawaroh², Nanang Wiyono², Yunia Hastami² \\ ${ }^{1}$ Program Studi Kedokteran Fakultas Kedokteran Universitas Sebelas Maret, Surakarta - INDONESIA \\ ${ }^{2}$ Departemen Anatomi Fakultas Kedokteran Universitas Sebelas Maret, Surakarta - INDONESIA
}

Submitted: 09 Jan 2020; Final Revision from Author: 23 Jan 2020; Accepted: 06 Mar 2020

\section{ABSTRACT}

Background: Anatomy is a basic science needed by clinicians in order to perform medical procedures safely and effectively. Nowadays, the amount of time available for teaching anatomy is reduced because of the introduction of new subjects to medical program. Whereas, the anatomy itself is already too complex to learn, especially neuroanatomy. As the result, medical students tend to find difficulties in mastering anatomy. In fact, inadequate understanding of anatomy has an impact to medical errors. The aim of this study is to compose neuroanatomy learning objectives based on consensus of anatomy lecturers in Indonesia.

Methods: Two-rounds Delphi process was employed in this qualitative study. Twenty anatomy lecturers from all over Indonesia were recruited as panels based on purposive sampling technique. Panels of first round of Delphi were requested to compose learning objectives based on neuroanatomy core syllabus available in the questionnaire. They had to list each learning objective with cognitive level according to Bloom's taxonomy. In the second round, panels were asked to score each learning objectives based on their level of importance from 1 to 4 . Learning objectives scored 3 or 4 by $60 \%$ panels were qualified as the final results.

Results: 66 learning objectives were obtained in the first round of Delphi and became 68 due to modification process conducted by expert. In the second round, 67 learning objective were achieved, and became 52 after final process of expert modification. The learning objectives cognitive level varied in C1-C3 according to Bloom's Taxonomy.

Conclusion: This study obtained 52 learning objectives of neuroanatomy.

Keywords: anatomy lecturers consensus, learning objectives, anatomy, neuroanatomy, delphi process

\section{ABSTRAK}

Latar belakang: Anatomi merupakan ilmu dasar yang penting bagi seorang dokter dalam melakukan pemeriksaan klinis. Bertambahnya ilmu baru dalam kurikulum kedokteran membuat alokasi jam belajar anatomi menjadi berkurang. Padahal materi yang diajarkan cukup banyak dan kompleks, terutama materi anatomi sistem saraf. Akibatnya mahasiswa merasa kesulitan dalam menguasai materi anatomi. Pemahaman anatomi yang kurang adekuat dapat menyebabkan kesalahan dalam praktik klinis. Tujuan penelitian ini untuk membuat konsensus pengajar anatomi dari berbagai fakultas kedokteran di Indonesia mengenai tujuan pembelajaran anatomi sistem saraf.

*corresponding author, contact: gabriellaclaudia1@gmail.com 
Metode: Penelitian ini merupakan penelitian kualitatif menggunakan metode Delphi dua putaran. Subjek penelitian ialah 20 dosen anatomi yang berasal dari seluruh Indonesia yang dipilih melalui purposive sampling. Responden pada Delphi putaran pertama responden diminta untuk memilih domain kognitif sesuai taksonomi Bloom lalu menyusun kalimat tujuan pembelajaran pada poin-poin materi inti anatomi. Selanjutnya pada Delphi putaran kedua responden diminta untuk menentukan tingkat pentingnya suatu tujuan pembelajaran dari nilai 1-4. Level konsensus yang ditetapkan sebesar $60 \%$ untuk yang memilih nilai 3 dan 4.

Hasil: Delphi putaran pertama menghasilkan 66 tujuan pembelajaran dan dimodifikasi oleh Ahli menjadi 68 tujuan pembelajaran. Delphi putaran kedua menghasilkan 67 tujuan pembelajaran dan dimodifikasi oleh Ahli menjadi 52 tujuan pembelajaran. Tujuan pembelajaran tersebut berada pada domain kognitif C1-C3.

Kesimpulan: Didapatkan 52 tujuan pembelajaran anatomi sistem saraf.

Kata kunci: konsensus dosen anatomi, tujuan pembelajaran, anatomi, sistem saraf, metode delphi

\section{PRACTICE POINTS}

- Penyusunan naskah publikasi mengenai tujuan pembelajaran anatomi sistem saraf mahasiswa kedokteran merupakan yang pertama di Indonesia dengan melibatkan perwakilan dosen anatomi se-Indonesia.

- Hasil penelitian dapat digunakan untuk memperjelas dan menyeragamkan tujuan pembelajaran anatomi sistem saraf dalam mencapai kompetensi minimal mahasiswa kedokteran di Indonesia.

- Hasil penelitian memberikan manfaat sebagai masukan untuk pembelajaran anatomi sistem saraf di Indonesia.

\section{PENDAHULUAN}

Anatomi merupakan salah satu ilmu dasar penting dalam pendidikan kedokteran. Penguasaan dasar anatomi yang kuat dapat menunjang seorang dokter dalam melakukan pemeriksaan fisik, melakukan diagnosis, menafsirkan pencitraan, serta melakukan prosedur klinis yang aman dan efektif. ${ }^{1}$ Terapi invasif minimal di bidang kedokteran juga sedang berkembang seiring dengan kemajuan teknik pencitraan tiga dimensi. Dalam hal ini, ilmu anatomi diperlukan oleh klinisi untuk memahami jalan menuju target organ spesifik pada terapi invasif minimal tersebut. ${ }^{2}$

Secara global, sedang terjadi tren perubahan pembelajaran kedokteran yang berdampak pada pengurangan jam belajar biomedik dasar, termasuk anatomi. Hal ini disebabkan adanya pengembangan ilmu pengetahuan kedokteran yang cukup pesat sehingga materi pembelajaran yang berbasis praktik klinis dan skill pada mahasiswa kedokteran lebih difokuskan. ${ }^{3}$
Kini masih terjadi perdebatan tentang pengetahuan anatomi yang dianggap penting dan diperlukan bagi mahasiswa kedokteran. Ada yang menekankan perlunya menguasai tubuh manusia secara keseluruhan, dan yanglain menekankan pengurangan konten pembelajaran anatomi supaya sesuai konteks dan relevan secara klinis saja. ${ }^{4}$ Perdebatan tersebut didasarkan karena masih ditemukannya medical error maupun kesulitan dalam pemecahan masalah di antara lulusan pendidikan dokter saat memasuki fase klinik di rumah sakit. Hal ini disebabkan karena kurang kuatnya pengetahuan anatomi. ${ }^{1}$ Dengan demikian, diperlukan adanya kesepakatan dari para pakar mengenai batas minimum pengetahuan anatomi yang diperlukan bagi mahasiswa kedokteran untuk mencapai efektivitas dalam praktik klinik.

Cabang ilmu anatomi yang dianggap paling sulit oleh mahasiswa kedokteran ialah anatomi sistem saraf, atau dikenal juga dengan istilah neuroanatomi. Banyaknya materi sistem saraf yang harus dipelajari dengan jumlah waktu yang terbatas menyebabkan 
materi kurang dapat dipahami dengan baik. Hal ini ditakutkan dapat meningkatkan kecemasan mahasiswa kedokteran dalam mempelajari anatomi sistem saraf, sehingga memengaruhi sikap terhadap disiplin ilmu tersebut di kemudian hari. ${ }^{5}$ Anatomi sistem saraf sendiri merupakan cabang ilmu yang sedang berkembang pesat dan masih banyak diteliti, termasuk oleh para pengajar di universitas. Pengetahuan baru dari hasil penelitian di-update setiap waktu. Hal tersebut terkadang membuat para pengajar yang melakukan penelitian menambahkan bahan ajar anatomi sistem saraf sesuai dengan hasil penelitian terbaru. Akan tetapi, tentu saja mahasiswa tidak bisa diharapkan untuk menguasai semua materi anatomi sistem saraf terbaru yang diajarkan karena berbagai keterbatasan. ${ }^{3}$ Untuk itu, diperlukan adanya perbaikan pendidikan anatomi sistem saraf dengan penyusunan materi inti dan tujuan pembelajaran yang jelas.

Menanggapi hal tersebut, sudah ada beberapa penelitian mengenai penyusunan materi inti anatomi bagi mahasiswa kedokteran untuk cabang ilmu anatomi sistem saraf di Inggris, seperti penelitian yang dilakukan oleh Moxham et al. ${ }^{3}$ Ada juga penelitian yang menyusun silabus materi saraf terkait regio kepala leher seperti yang dilakukan oleh Tubbs et al. ${ }^{6}$ Di Indonesia sudah ada penelitian mengenai konsensus pakar anatomi mengenai poin materi inti anatomi sistem digestif yang ditulis oleh Munawaroh et al. ${ }^{7}$ dan untuk sistem saraf oleh Kusuma ${ }^{8}$ namun belum ada penelitian terkait penyusunan tujuan pembelajaran sistem saraf yang pernah dipublikaskan. Berdasarkan fenomena di atas, peneliti tertarik untuk menyusun konsensus dosen anatomi terkait tujuan pembelajaran anatomi sistem saraf untuk mahasiswa kedokteran.

\section{METODE}

Penelitian ini merupakan penelitian kualitatif yang menggunakan metode Delphi dua putaran. Populasi penelitian merupakan dosen anatomi seluruh fakultas kedokteran Indonesia yang dipilih sebanyak
20 orang sebagai subjek penelitian atau panel. Pemilihan panel menggunakan teknik purposive sampling dengan kriteria inklusi dosen yang telah mengajar anatomi minimal 3 tahun dan berlatar belakang pendidikan S1 dokter umum.

Putaran pertama Delphi dilaksanakan menggunakan kuesioner dari modifikasi hasil penelitian Kusuma. ${ }^{8}$ Putaran pertama ini melibatkan 6 orang panel menyusun poin-poin materi inti pada kuesioner menjadi tujuan pembelajaran beserta level kognisinya menurut Taksonomi Bloom.

Hasil dari putaran pertama Delphi disusun dan dimodifikasi oleh Ahli menjadi kuesioner Delphi putaran kedua. Ahli yang dimaksud merupakan dosen anatomi yang telah mengajar anatomi sistem saraf lebih dari 15 tahun. Putaran kedua melibatkan 20 orang panel yang diminta untuk menilai setiap tujuan pembelajaran yang telah disusun dengan skala 1-4 dan boleh disertai saran atau masukan. Pada putaran kedua ini ditetapkan level konsensus sebesar $60 \%$ untuk tujuan pembelajaran dengan nilai 3 dan 4. Hasil akhir tujuan pembelajaran didapatkan setelah melalui konsultasi Ahli.

\section{HASIL DAN PEMBAHASAN}

Panel pada penelitian ini terdiri atas 20 dosen anatomi yang mengajar di berbagai Fakultas Kedokteran di 14 kota yang tersebar di pulau Sumatera, Jawa, Lombok, Kalimantan, Sulawesi, dan Papua. Usia Panel bervariasi antara 30-52 tahun.

Kuesioner awal terdiri atas 182 materi inti, yang disusun menjadi 66 poin tujuan pembelajaran oleh panel pada putaran pertama. Kemudian hasil tersebut dikonsulkan kepada Ahli sehingga didapatkan 68 tujuan pembelajaran untuk disebar pada putaran kedua. Hasil dari putaran kedua yaitu sejumlah 67 tujuan pembelajaran yang disepakati oleh panel. Akan tetapi, tujuan pembelajaran tersebut mengalami modifikasi dan reduksi oleh Ahli dengan mempertimbangkan saran dari panel. Hasil akhir didapatkan 52 tujuan pembelajaran yang dirangkum pada Tabel 1 . 
Tabel 1. Rangkuman Tujuan Pembelajaran Menurut Topik Hasil Metode Delphi

\begin{tabular}{|c|c|c|c|c|c|}
\hline No. & Topik Sistem Saraf & $\begin{array}{l}\text { Jumlah Tujuan } \\
\text { Pembelajaran } \\
\text { Hasil Putaran } \\
\text { Pertama }\end{array}$ & $\begin{array}{l}\text { Modifikasi } \\
\text { Ahli Putaran } \\
\text { Pertama }\end{array}$ & $\begin{array}{l}\text { Jumlah Tujuan } \\
\text { Pembelajaran } \\
\text { Hasil Putaran } 2\end{array}$ & $\begin{array}{c}\text { Modifikasi } \\
\text { Ahli Putaran } \\
\text { Kedua }\end{array}$ \\
\hline 1. & Aspek Umum Sistem Saraf & 1 & 3 & 3 & 3 \\
\hline 2. & Hemispherium Cerebri & 9 & 9 & 9 & 5 \\
\hline 3. & Area Cortex dan Lobus & 6 & 6 & 6 & 6 \\
\hline 4. & $\begin{array}{l}\text { Diencephalon dan Kelenjar } \\
\text { Pituitary }\end{array}$ & 6 & 6 & 6 & 5 \\
\hline 5. & $\begin{array}{l}\text { Truncus Cerebri dan } \\
\text { Cerebellum }\end{array}$ & 5 & 5 & 5 & 4 \\
\hline 6. & $\begin{array}{l}\text { Formatio Reticularis dan } \\
\text { Systema Limbicus }\end{array}$ & 3 & 3 & 3 & 1 \\
\hline 7. & Vaskularisasi Otak & 6 & 6 & 6 & 4 \\
\hline 8. & Meninges & 4 & 4 & 3 & 3 \\
\hline 9. & Liquor Cerebrospinal & 2 & 2 & 2 & 2 \\
\hline 10. & Blood Brain Barrier & 3 & 3 & 3 & 1 \\
\hline 11. & Medulla Spinalis & 6 & 6 & 6 & 6 \\
\hline 12. & Nervi Craniales & 12 & 12 & 12 & 10 \\
\hline 13. & Nervi Spinales & 2 & 2 & 2 & 1 \\
\hline 14. & Sistem Saraf Otonom & 1 & 1 & 1 & 1 \\
\hline & Total & 66 & 68 & 67 & 52 \\
\hline
\end{tabular}

Peneliti menggunakan Delphi dua putaran untuk mendapatkan konsensus mengenai tujuan pembelajaran anatomi sistem saraf untuk mahasiswa kedokteran. Metode ini serupa dengan yang digunakan dalam penelitian Smith et $\mathrm{al}^{4}$ dan Munawaroh et $\mathrm{al}^{7}$ dan dipilih oleh peneliti karena terbukti sebagai metode yang paling efektif dalam penyusunan konsensus, sehingga sudah sering dipakai dalam penyusunan kurikulum kedokteran. ${ }^{9}$ Hasil penelitian ini diharapkan dapat menjadi rekomendasi dalam melengkapi kurikulum anatomi sistem saraf, seperti yang sudah tersusun dalam buku standar kurikulum anatomi yang ditulis oleh Perhimpunan Ahli Anatomi Indonesia. ${ }^{10}$

Kuesioner Delphi putaran pertama dikonsultasikan terlebih dahulu kepada ahli sebelum disebarkan kepada panel. Ahli memodifikasi 185 materi inti yang berasal dari penelitian Kusuma $^{8}$ menjadi
182 materi. Hal ini disebabkan karena terdapat beberapa pengulangan dari materi inti yang sama, namun berada dalam topik berbeda. Misalnya materi vaskularisasi arteri hemispherium cerebri yang masuk pada topik vaskularisasi otak dan topik area cortex dan lobus.

Delphi putaran pertama menghasilkan 66 poin tujuan pembelajaran yang dirangkum dari 182 materi inti topik sistem saraf tersebut. Poin-poin tujuan pembelajaran tersebut hanya berada dalam level kognisi C1 (mengetahui), C2 (menjelaskan), dan C3 (mengaplikasikan). Tidak didapatkan tujuan pembelajaran dengan level kognisi C4 (menganalisis), C5 (mengevaluasi), dan C6 (mencipta) karena level tersebut termasuk dalam kemampuan berpikir tingkat tinggi atau dikenal dengan istilah High Order Thinking Skill (HOTS). ${ }^{11}$ Kemampuan tersebut dapat dicapai apabila mahasiswa dapat menghubungkan 
ilmu anatomi dengan ilmu-ilmu kedokteran lainnya.

Ahli anatomi menambahkan 2 tujuan pembelajaran pada kuesioner sebelum diputarkan pada putaran kedua. Kedua tujuan pembelajaran tersebut berada pada topik aspek umum sistem saraf, meliputi: 1) Mahasiswa mampu mengaplikasikan pengetahuan mengenai organisasi susunan saraf pada gangguan sistem terkait (C3); dan 2) Mahasiswa mampu mengaplikasikan pengetahuan mengenai neuroembriologi pada gangguan sistem terkait (C3), sehingga pada kuesioner putaran kedua terdapat 68 tujuan pembelajaran yang akan dinilai oleh panel. Kedua tujuan pembelajaran ini ditambahkan karena sebelumnya sudah tercantum pada buku silabus anatomi yang disusun oleh Perhimpunan Ahli Anatomi Indonesia, ${ }^{10}$ sedangkan pada penelitian Kusuma $^{8}$ tidak memuat poin materi inti terkait neuroembriologi dan organisasi susunan saraf pusat.

Terdapat 1 tujuan pembelajaran yang direduksi berdasarkan hasil putaran kedua Delphi dengan level konsensus sebesar $60 \%$, sehingga didapatkan 67 tujuan pembelajaran. Tidak terdapat persentasi reduksi yang besar pada putaran kedua ini, yaitu hanya sebesar $1,47 \%$, namun terdapat cukup banyak masukan dari panel. Mayoritas masukan yaitu berupa penggabungan kalimat tujuan pembelajaran karena memiliki poin inti yang mirip. Hal ini bertujuan untuk efisiensi agar masing-masing poin tujuan pembelajaran tidak saling tumpang tindih.

Masukkan lainnya berupa level kognisi yang naik dari C2 menjadi C3 seperti pada topik area cortex dan lobus di mana panel tersebut mengaharapkan pengetahuan mengenai area fungsional cortex cerebri dapat diaplikasikan pada klinis seperti kerusakan di area wernicke maupun area lainnya. Kerusakan pada area fungsional cortex cerebri dapat dideteksi melalui pemeriksaan fisik neurologi yang merupakan kompetensi 4A bagi dokter umum menurut SKDI. ${ }^{12}$

Terdapat juga panel yang mengkritik bahwa terdapat tujuan pembelajaran yang relatif sulit dipahami oleh mahasiswa, misalnya mengenai neuroembriologi pada topik aspek umum sistem saraf. Neuroembriologi sering kali dianggap sebagai materi yang paling sulit untuk dipelajari oleh mahasiswa kedokteran karena kompleksitasnya. ${ }^{13}$ Topik tersebut biasanya baru didalami saat lulusan dokter umum mengambil pendidikan kedokteran spesialis, terutama dari spesialis saraf dan anak..$^{14}$ Akan tetapi, lulusan dokter umum juga perlu untuk memahami dasar-dasar ilmu neuroembriologi untuk mendeteksi adanya malfomasi kongenital terkait sistem saraf. ${ }^{13}$ Materi organisasi susunan saraf pusat juga dikritik sebagai pembelajaran yang cukup rumit namun penting untuk dipelajari. Integrasi antarilmu biomedik dasar seperti anatomi, fisiologi, dan histologi diperlukan untuk memahami organisasi susunan saraf pusat secara mendalam, seperti yang digambarkan oleh Swanson dan Bota. ${ }^{15}$ Berdasarkan alasan tersebut, materi neuroembriologi dan organisasi susunan saraf pusat tetap dimasukkan sebagai tujuan pembelajaran, tetapi hanya berupa gambaran umum saja. Hal ini juga berlaku bagi tujuan pembelajaran vaskularisasi otak yang dianggap rumit dipelajari pada sistem saraf apabila belum mempelajari blok kardiovaskular, sehingga juga tetap dimasukkan dalam tujuan pembelajaran berupa gambaran umum.

Terdapat juga beberapa tujuan pembelajaran yang menurut segelintir panel lebih cocok bila dipelajari di ilmu kedokteran lainnya. Misalnya mengenai fungsi hemispherium cerebri yang lebih cocok pada ilmu faal, obat-obatan pada sawar darah otak yang lebih cocok pada ilmu farmakologi, dan fungsi neuron pada cornu anterior medula spinalis yang lebih cocok pada ilmu faal dan histologi. Akan tetapi, peneliti tetap memasukkan tujuan pembelajaran tersebut dengan alasan perlunya dasar anatomi untuk mengintegrasikan materi tersebut dalam bidang ilmu lain. Selain itu, mayoritas panel setuju bahwa tujuan pembelajaran tersebut bernilai penting dan sangat penting serta memenuhi level konsensus yang disyaratkan peneliti.

Peneliti kemudian mengonsultasikan saran-saran dari panel putaran kedua tersebut kepada Ahli. Selanjutnya, Peneliti mencoba menggabungkan, mengubah, dan menyusun kembali kalimat tujuan pembelajaran. Modifikasi tersebut menghasilkan 52 tujuan pembelajaran dari 67 tujuan pembelajaran yang disetujui panel berdasarkan level konsensus sebesar $60 \%$, di mana dapat disimpulkan bahwa terjadi reduksi sebesar 22,38\% dari hasil modifikasi putaran kedua. Daftar tujuan belajar yang akhirnya 
digunakan sesuai dengan konsensus akhir dapat dilihat pada bagian Lampiran pada akhir manuskrip ini.

\section{KESIMPULAN}

Didapatkan sebanyak 52 tujuan pembelajaran dari 185 poin materi inti pada penelitian ini. Tujuan pembelajaran tersebut terbagi dalam 14 topik, di antaranya: aspek umum sistem saraf sebanyak 3, hemispherium cerebri sebanyak 5 , area cortex dan lobus sebanyak 6, diencephalon dan kelenjar pituitary sebanyak 5 , truncus cerebri dan cerebellum sebanyak 4, formatio reticularis dan systema limbicus sebanyak 1 , vaskularisasi otak sebanyak 4 , meninges sebanyak 3, liquor cerebrospinal sebanyak 2, blood brain barrier sebanyak 1 , medulla spinalis sebanyak 6 , nervi craniales sebanyak 10 , nervi spinales sebanyak 1, dan sistem saraf otonom sebanyak 1 . Teridentifikasi domain kognitif C1 sebanyak 5 poin, C2 sebanyak 29 poin, dan C3 sebanyak 18 poin dari penelitian ini.

\section{SARAN}

Penelitian ini dapat disempurnakan dengan menambahkan panel pada putaran pertama agar hasil lebih representatif. Program studi kesehatan selain kedokteran juga dapat mengembangkan penelitian ini sesuai kebutuhan kurikulum.

\section{UCAPAN TERIMA KASIH}

Penulis mengucapkan terima kasih kepada semua pihak yang terlibat dalam penulisan laporan penelitian ini, terutama bagi dosen anatomi yang besedia menjadi panel.

\section{DEKLARASI KEPENTINGAN}

Para penulis mendeklarasikan bahwa tidak terdapat konflik kepentingan apapun terkait studi pada naskah ini.

\section{KONTRIBUSI PENULIS}

Gabriela Claudia - menyusun tinjauan pustaka, pembahasan, dan naskah publikasi; Siti Munawaroh: Menyusun metode Delphi dan meninjau ulang naskah publikasi; Nanang Wiyono: Meninjau ulang konten neuroanatomi pada kuesioner dan mengkoordinasi panel penelitian; Yunia Hastami: Menyusun rancangan penelitian dan hasil penelitian.

\section{DAFTAR PUSTAKA}

1. Swamy M, Venkatachalam S, McLachlan J. A delphi consensus study to identify current clinically most valuable orthopaedic anatomy components for teaching medical students. BMC Medical Education. 2014;14(1): 230.

2. Prakosa D. Menggagas pembelajaran anatomi pada kurikulum berbasis kompetensi untuk pendidikan kedokteran dasar. Jurnal Anatomi Indonesia. 2006;1(2).

3. Moxham B, McHanwell S, Plaisant O, Pais D. A core syllabus for the teaching of neuroanatomy to medical students. Clinical Anatomy. 2015; 28(6): pp.706-716..

4. Smith CF, Finn GM, Stewart J, McHanwell S. Anatomical Society core regional anatomy syllabus for undergraduate medicine: The delphi process. Journal of Anatomy.2016; 228(1): 2-14..

5. Hall SR, Stephens JR, Seaby EG, Andrade MG, Lowry AF, Parton WJ, Smith CF et al. Can medical students accurately predict their learning? A study comparing perceived and actual performance in neuroanatomy. Anatomical Sciences Education. 2016; 9(5):488-495.

6. Tubbs RS, Sorenson EP, Sharma A, Benninger B, Norton N, Loukas M, Moxham BJ. The development of a core syllabus for the teaching of head and neck anatomy to medical students. Clinical Anatomy. 2014; 27(3): 321-330.

7. Munawaroh S, Kartikasari MND, Hermasari BK. Konsensus pakar anatomi indonesia mengenai materi inti anatomi sistem pencernaan. JURNAL BIOMEDIK. 2018; 10(1).

8. Kusuma, LP. Konsensus dokter umum mengenai materi inti anatomi sistem saraf untuk mahasiswa program studi kedokteran. (Skripsi). Surakarta: Universitas Sebelas Maret; 2018.

9. Kumar N, Swift A, Rahman, E. Development of "core syllabus" for facial anatomy teaching to aesthetic physicians: A Delphi consensus. Plastic 
and Reconstructive Surgery Global Open. 2018; 6(3): $1-7$.

10. Perhimpunan Ahli Anatomi Indonesia. Buku standar kurikulum anatomi. Jakarta: PAAI;2019. pp. 10-11.

11. Wirda M., Berutu N, Rosni R. Developing of the demography teaching book based on KKNIcurriculum and high order thinking skills. 1st International Conference on Social Sciences and Interdisciplinary Studies (ICSSIS 2018). 2019;208: 111-117

12. KKI. Standar kompetensi dokter Indonesia. Jakarta: Konsil Kedokteran Indonesia; 2012.

13. Cuoco JA, Hoehmann CL, Edwards DM. Neuroembryology and congenital disorders of the nervous system: A primer for medical students. Edorium Journal of Neurology. 2016;(3):17-25.

14. Sarnat HB. Neuroembryology education for paediatric neurology and neuropathology trainees in canada. Canadian Journal of Neurological Sciences. 2010;37(1):105-109.

15. Swanson LW, Bota M. Foundational model of structural connectivity in the nervous system with a schema for wiring diagrams, connectome, and basic plan architecture. Proceedings of the National Academy of Sciences. 2010;107(48):20610-20617. 


\section{LAMPIRAN}

Tujuan Pembelajaran Anatomi Sistem Saraf

No. Tujuan Pembelajaran

1. ASPEK UMUM SISTEM SARAF

1.1 Mahasiswa mampu mengaplikasikan pengetahuan mengenai gambaran umum organisasi susunan saraf pada gangguan sistem terkait

1.2 Mahasiswa mampu mengaplikasikan pengetahuan mengenai gambaran umum neuroembriologi pada gangguan sistem terkait

1.3 Mahasiswa mampu menjelaskan dan menguraikan konsep persarafan segmental kulit/ dermatom dan konsep persarafan segmental/otot

\section{HEMISPHERIUM CEREBRI}

2.1 Mahasiswa mampu menjelaskan dan menguraikan struktur dan morfologi hemispherium cerebri

2.2 Mahasiswa mampu mengidentifikasi dan menjelaskan sulcus dan gyrus yang berfungsi pokok pada cortex cerebri

2.3 Mahasiswa mampu mengidentifikasi dan menjelaskan pembagian lobus pada hemispherium cerebri beserta fungsinya secara umum

2.4 Mahasiswa mampu mengidentifikasi dan menjelaskan mengenai komponen ganglia basalis serta menghubungkannya dengan klinis

2.5 Mahasiwa mampu mengidentifikasi dan menunjukkan letak substansia alba serta mengklasifikasikan komponennya

\section{AREA CORTEX DAN LOBUS}

3.1 Mahasiswa mampu menjelaskan dan menggunakan pengetahuan anatomi tentang lokasi, dan fungsi lobi (frontalis, parietalis, occipitalis, temporalis), serta area fungsional cortex cerebri untuk menginterpretasi hasil pemeriksaan klinis neurologis

3.2 Mahasiswa mampu menjelaskan struktur, letak, serta fungsi systema limbicus dan insula. serta mengaplikasikannya pada pemeriksaan klinis

3.4 Mahasiswa mampu mengidentifikasi, menjelaskan mengenai lesi area cortex, lesi broca, sensoris, prefrontal, visual, dan auditori serta menghubungkannya dengan klinis

3.5 Mahasiswa mampu menunjukkan dan menjelaskan area wernicke, pengecap, dan sulcus centralis serta mengaplikasikannya dalam pemeriksaan klinis

3.6 Mahasiswa mampu menunjukkan dan menjelaskan area wernicke, pengecap, dan sulcus centralis serta mengaplikasikannya dalam pemeriksaan klinis

\section{DIENCEPHALON DAN KELENJAR PITUITARY}

4.1 Mahasiswa mampu menunjukkan dan menjelaskan topografi thalamus, epithalamus, dan subthalamus

4.2 Mahasiswa mampu menjelaskan fungsi thalamus dan chiasma opticum

4.3 Mahasiswa mampu mengingat kembali, menunjukkan, menjelaskan hipothalamus serta mengubungkannya dengan klinis

4.4 Mahasiwa mampu mengingat kembali dan menunjukkan lokasi dan hubungan hipothalamus dengan kelenjar pituitary

4.5 Mahasiswa mampu menunjukkan dan menjelaskan kontrol hipofisis dan pinsip umum neuroendokrinologi 
5.

5.1 Mahasiswa mampu menunjukkan dan mengidentifikasi topografi dan bagian-bagian

$\mathrm{C} 1$ truncus cerebri (mesencephalon, pons varolli, dan medulla oblongata) serta menjelaskan fungsinya secara umum

5.2 Mahasiswa mampu menunjukkan dan menjelaskan lokasi dan struktur external mesencephalon

5.3 Mahasiswa mampu mengidentifikasi dan menjelaskan fungsi substansia nigra

5.4 Mahasiswa mampu mengidentifikasi, menunjukkan, menjelaskan cerebellum dan menghubungkannya dengan klinis.

6. FORMATIO RETICULARIS DAN SYSTEMA LIMBICUS

6.1 Mahasiswa mampu menunjukkan dan menjelaskan lokasi dan fungsi umum formatio reticularis serta hubungannya dengan jaras systema limbicus

\section{VASKULARISASI OTAK}

7.1 Mahasiswa mampu menjelaskan gambaran umum struktur vaskuler otak dan cabangcabang utamanya (A. Cerebri Media, A. Cerebri Anterior, A. Cerebri Posterior, dan A. Carotis Communis)

7.2 Mahasiswa mampu menjelaskan vena emissaria dengan klinis

7.4 Mahasiswa mampu menjelaskan plexus venosus, A. Facialis, A. Ophtalmica, V. jugularis interna, dan bulbus superius vena jugularis interna (BSVJI)

\section{8. $\quad$ MENINGES}

8.1 Mahasiswa mampu menjelaskan struktur dan fungsi meninges serta aplikasi klinisnya apabila terjadi perdarahan intracranial dan meninges (extradural, subdural, subarachnoid)

8.2 Mahasiswa mampu menguraikan dan menjelaskan vaskularisasi meninges oleh A/V meningea media

8.3 Mahasiswa mampu menguraikan dan menjelaskan innervasi dura mater oleh N. ophtalmicus, N. maxillaris, dan N. vagus

9. LIQUOR CEREBROSPINAL

9.1 Mahasiswa mampu menunjukkan dan menjelaskan topografi ventrikuli cerebri serta menghubungkannya dengan klinis

9.2 Mahasiswa mampu menjelaskan perjalanan sirkulasi, sekresi dan absorbsi LCS, susunan LCS, fungsi LCS, serta pemeriksaan LCS

\section{BLOOD BRAIN BARRIER}

10.1 Mahasiswa mampu menjelaskan dan menguraikan struktur dan fungsi umum sawar darah otak dan hubungannya dengan obat-obatan dan trauma otak

11. MEDULLA SPINALIS

11.1 Mahasiswa mampu menyebutkan struktur anatomi, topografi, dan fungsi medulla spinalis

$\mathrm{C} 1$

11.2 Mahasiswa mampu menyebutkan dan mengidentifikasi struktur anatomi external dan internal medulla spinalis

11.3 Mahasiswa mampu menjelaskan susunan meninges pada medulla spinalis

11.4 Mahasiswa mampu menjelaskan gambaran umum fungsi neuron pada struktur anatomi medulla spinalis 
11.5 Mahasiswa mampu menyebutkan dan menjelaskan secara umum tractus ascendens dan descendens medulla spinalis

11.6 Mahasiswa mampu menjelaskan vaskularisasi arteri dan vena pada medulla spinalis

12. NERVI CRANIALES

12.1 Mahasiswa mampu menjelaskan anatomi dan fungsi nervi craniales

12.2 Mahasiswa dapat menggunakan pengetahuan tentang jaras Nn. Craniales I-XII beserta percabangannya untuk menginterpretasi hasil pemeriksaan klinis neurologi

12.3 Mahasiswa mampu menyebutkan dan menjelaskan neuralgia trigeminal dan menghubungkannya dengan klinis

12.4 Mahasiswa mampu menjelaskan cabang-cabang N. Facialis

12.5 Mahasiswa mampu menjelaskan secara umum mengenai plexus parotid

12.6 Mahasiswa mampu menjelaskan gambaran umum refleks kornea

12.7 Mahasiswa mampu menjelaskan jalur lesi penglihatan dan menghubungkannya dengan klinis

12.8 Mahasiswa mampu menjelakan jalur lesi pendengaran dan menghubungkannya dengan klinis

12.9 Mahasiswa mampu menjelaskan refleks sinus caroticus

12.10 Mahasiswa mampu menjelakan refleks menelan dan meludah

13. NERVI SPINALES

13.1 Mahasiswa dapat menjelaskan secara umum lokasi dan area yang diinervasi plexus brachialis dan lumbosacralis serta menginterpretasi data hasil pemeriksaan klinis

14. SISTEM SARAF AUTONOM

14.1 Mahasiswa dapat menjelaskan anatomi, prinsip kerja sistem saraf autonom, serta efek simpatis dan parasimpatis pada tubuh dan kelenjar secara umum 